\section{AETIOLOGY OF INTUSSUSCEPTION IN CHILDREN}

BY

\author{
E. G. KNOX, M.D., M.R.C.P.
}

S. D. M. COURT, M.D., F.R.C.P.

AND

\section{P. S. GARDNER, M.D., Dip.Bact.}

From the Department of Child Health, King's College, University of Durham, and the Department of Bacteriology. Royal Victoria Infirmary, Newcastle upon Tyne

The aetiology of intussusception is still not fully understood, but two main theories have been advanced, the dietary and the infective. The dietary theory was derived partly from the age distribution of the disease, with its maximum incidence about the time of weaning, and partly from the clinical impression that affected infants were unusually fat and presumably very well fed. The possible role of infection was supported by the frequent history of mild respiratory or alimentary symptoms preceding the abrupt onset of pain and vomiting, and the almost constant finding at operation of large mesenteric lymph nodes. These show the histological changes of inflammation, and the known association of intussusception 'with typhoid suggested that some unidentified infection of the lymph nodes and of Peyer's patches might be involved. The recent finding of adenoviruses in both mesenteric glands and intestinal contents reinforces the infective hypothesis and suggests that virus infection may well play an important part (Gardner, 1961 ; Ross and Potter, 1961 ; Zachary and Potter, 1961).

The dietary and infective theories are not contradictory. The disease "intussusception" is defined in mechanical terms, is treated by mechanical means, and in certain children has an obvious mechanical cause, and it seemed to us that a general hypothesis of its pathogenesis might also be made in mechanical and hydrodynamic terms. Consequently it was unlikely that any specific cause would be found which is both necessary and sufficient, which is always present before the disease, and which, when present, is always followed by the disease. Rather we should expect a group of interacting factors any of which might alter the mechanics of the intestine through the effects of excessive fluid-flow rates, obstruction, narrowing, or by inducing abnormal segmental contractions.

We have shown (Court and Knox, 1959) that intussusception is almost three times as frequent in Newcastle as in Birmingham (MacMahon, 1955), and subsequent estimates from Edinburgh, Sheffield, and Aberdeen (Smith, 1960 ; Steyn and Kyle, 1961 ; Ross and Potter, 1961) suggest that the Newcastle figure is abnormally high. Bearing in mind the general similarity of climate and living conditions in these different communities, it seemed that an explanation for these differences of incidence might be found in differing habits of infant care, as in feeding methods or the use of purgatives, rather than from different infection rates.

However, we did not on these grounds prejudge the issue of infection as a factor in the aetiology even if it - seemed unlikely that it would alone explain the regional variations, and we decided to investigate simultaneously feeding and drug administration in children with intussusception and the frequency of recent symptoms suggesting infection in the affected children or in members of their households, and to search for viruses.

The present study is concerned mainly with the clinical and epidemiological data. This emphasis is deliberate because we feel that the virus studies demand a different form of presentation, and these will be published later when completed. However, the possible relationships between the two kinds of evidence are considered at the end of this paper.

\section{Materials and Methods}

The material presented is in two parts. The first is derived from the case records of 100 consecutive infants with intussusception admitted to the Royal Victoria Infirmary, Newcastle upon Tyne, during February, 1957, to December, 1959 . The diagnosis in every case was confirmed by operation or barium enema.

The second part consists of the answers to particular questions put to the mothers of new cases of intussusception in children under 2 years of age between January, 1960, and October, 1961. The same questions were put to the mothers of a series of age-matched normal babies attending child-welfare centres in Newcastle upon Tyne. The mothers of bottle-fed babies, both cases and controls, were also asked to supply the teat or teats in current use. Altogether 35 cases of intussusception and 32 controls were questioned. The deficiency in the number of controls was due to the difficulty of finding an age-matched pair within a reasonable period for a few of the older children, an age-group less frequently seen at child welfare centres.

\section{Growth Rates}

Our evidence on growth comes from 100 case histories reviewed retrospectively. Birth weights as remembered by the mother at the time of admission were recorded in 98 cases-61 boys and 37 girls. The mean birth weight was $7 \mathrm{lb} .8 \mathrm{oz}$. $(3,400 \mathrm{~g}$.) and the normal mean value derived from the Ministry of Health (1959) study adjusted to the observed sex ratio was $7 \mathrm{lb}$. $6 \mathrm{oz}$. $(3,345$ g.). Although methods of ascertainment were different there is no evidence here that children with intussusception were of other than normal birth weight. MacMahon (1955) made the same observation. We felt justified, therefore, in using weights observed at the time of the illness as indices of actual growth.

Only in a few cases was a previous recent weight record available, but 75 of the 100 were weighed in hospital. Where more than one weight was available we have used the one nearest to the time of discharge. Almost all weighings were made on the actual day of discharge. The majority of the children reached hospita] on the first or second day of the illness and stayed in hospital for two days; only 7 of the 100 remained for more than four days. In most instances the weights were taken about three days after the onset of the disease.

Unfortunately the relationship between this measurement and the weight before onset is uncertain. Affected children must lose weight from vomiting and refusal of feeds, but much of this will have been replaced by the time of discharge. We consider it unlikely that the balance of illnoss and resuscitation results in a net gain, and weigh: on discharge is more likely to represent 
an underestimate of weights before onset, but we cannot be certain.

Table I gives the weights of these 75 children in relationship to the means for normal infants of the same age (Ministry of Health, 1959). This shows that signi-

TABle I.-Relationship to Normal Mean Weight, by Age, of Weights of Infants with Intussusception

\begin{tabular}{r|c|c|c|c|c|c|c}
\hline Age in Days: & -50 & -100 & -150 & -200 & -250 & -300 & -365 \\
\hline $\begin{array}{l}\text { Greater than normal mean } \\
\text { Less ", ", " }\end{array}$ & 0 & $\mathbf{0}$ & $\mathbf{1 7}$ & $\mathbf{8}$ & $\mathbf{3}$ & $\mathbf{5}$ & 4 \\
\hline
\end{tabular}

$\chi_{(1)}^{2}$ for infants up to 150 days $=8.76 ; P<0.005$.

Each infant was classified in relation to the normal mean weight for the appropriate sex and the exact age in days before entry into the age-groups usped in the table.

ficantly more than half of the affected children under 5 months of age, but not the older ones, were heavier than the normal mean weight. The normal median, if available, would have been a better criterion than the mean and because of the skew of the weight distribution would probably have shown this difference more clearly.

From this finding, together with the observation on birth weights, we infer that the actual rate of growth has been excessive in these infants and that this is probably associated with an excessive food intake.

\section{Time of Onset}

The question arises whether the supposed dietary factor is associated with the disease only in some indirect way or directly and perhaps causally at the time of an individual feed. As the hour of onset might offer evidence on this point it was analysed.

The time of onset was often known exactly and was stated to the nearest hour in 91 of the first 100 children. There was a clear diurnal variation, and since the same feature was found among the 35 cases questioned later Table II contains the times of onset for all the cases

TABLE II.-Diurnal Variation of Times of Onset of Intussusception

\begin{tabular}{|c|c|c|c|c|c|c|c|c|c|c|c|c|c|}
\hline $\begin{array}{l}\text { Hour of } \\
\text { Day: }\end{array}$ & $\begin{array}{c}\text { ô } \\
\text { ô } \\
\text { }\end{array}$ & 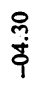 & $\begin{array}{l}\text { ̊ } \\
\text { \&ें }\end{array}$ & $\begin{array}{l}\text { o } \\
\infty \\
\text { o̊ } \\
\text { î }\end{array}$ & 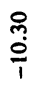 & 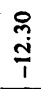 & $\frac{\stackrel{\rho}{+}}{+!}$ & $\begin{array}{l}\stackrel{0}{\tilde{n}} \\
\stackrel{0}{0}\end{array}$ & $\begin{array}{l}\text { ᄋ్ల } \\
\frac{\infty}{1}\end{array}$ & $\begin{array}{l}\text { ্̊ల } \\
\text { ণ্ণ }\end{array}$ & $\begin{array}{l}\text { ָิ } \\
\text { ণิ }\end{array}$ & $\begin{array}{l}\text { ্̊ } \\
\text { \&̊ }\end{array}$ & 胥 \\
\hline $\begin{array}{c}\text { No. of } \\
\text { cases }\end{array}$ & +3 & 4 & 12 & 22 & 14 & 21 & 19 & 9 & 6 & 6 & 8 & 2 & 126 \\
\hline
\end{tabular}

An additional nine cases had onsets insufficiently precise for inclusion in his table.

in both groups where this was recorded with reasonable precision. So far as we know, this diurnal variation, with the majority of onsets between 5 a.m. and 5 p.m., has not previously been recorded.

However, in the majority the onset did not occur while the children were actually feeding but while they were resting or playing. In the prospective study we collected details of the last meal before the onset and its time in relation to the first symptom; these intervals are given in Table III and show that in the majority the onset was more than one hour after a feed. This is not entirely incompatible with a direct fluid-loading effect, since we do not know how long the stomach took to empty in these children, but the number in

TABLE III.-Interval Between Onset and the Beginning of Last

\begin{tabular}{|c|c|c|c|c|c|c|}
\hline & \multicolumn{6}{|c|}{ Feed } \\
\hline Minutes: & $0-30$ & -60 & -120 & -180 & $\begin{array}{c}\text { Over } \\
180\end{array}$ & $\begin{array}{l}\text { Indeter- } \\
\text { minate }\end{array}$ \\
\hline No. of cases & 4 & 3 & 7 & 5 & 11 & 5 \\
\hline
\end{tabular}

which the onset occurred more than three hours after a feed is striking. In several it occurred on waking and before the first feed of the day.

\section{Food and Fluid Intakes}

It was hoped to estimate for each child the total intake of calories and fluid per day. The former proved impracticable largely owing to the vague amounts of cereal used in very many of the diets, but an estimate of fluid intake was possible. This was reasonably straightforward in babies fed fully on the bottleirregular feeds being averaged out fairly satisfactorily to an estimate for each day. The fluid intake of children fed entirely or partly by cup or by spoon was estimated less satisfactorily than with bottle-feeds, but most mothers seemed able to give a fairly precise estimate of each feed in terms of ounces. In these children the estimate was limited to fluid taken as drinks. A usable estimate was reached in all the 35 index cases and in 28 of the controls.

The stated fluid intakes varied from 10 to $48 \mathrm{oz}$. $(285$ to $1,365 \mathrm{ml}$.) per day. The mean value for both groups was $28.8 \mathrm{oz}$. $(820 \mathrm{ml}$.) per day. In the 11 affected infants aged less than 6 months the mean intake was higher than in the age-matched controls-31.5 oz. (895 ml.) compared with $27.8 \mathrm{oz}$. (790 ml.). This is in the same direction as the differences based on weight on discharge, but is not significant.

\section{Feeding Techniques}

One of the 35 children with intussusception was partly breast-fed and two controls were fully breast-fed. All the others in both groups were fed by bottle or cup or spoon, or by a combination of these. One child was fed on canned evaporated milk and several others were fed entirely on bottled cows' milk, but 28 patients and 23 controls were still having some feeds of reconstituted dried milk. There were no evident differences between the groups in any of these respects.

Of the 35 with intussusception, 30 were having at least one bottle a day. A rather smaller proportion of controls were bottle-fed, 24 out of 32 . The mean numbers of bottle-feeds a day were 3.1 for the patients and 2.8 for the controls ; 20 patients but only 14 controls were having 4 or more bottle-feeds a day. These comparisons are concordant in direction, but none of the differences is significant.

The technique of making up feeds was examined in detail, and here a wider difference between the groups was found. This related to the addition of cereal foods to the bottle-feeds. Such additions were made in 7 of the 30 bottle-fed patients and in 13 of the 24 bottlefed controls, and the difference in proportions is statistically significant at the $5 \%$ level.

\section{Teats}

When an infant was bottle-fed all the teats in current use were asked for ; they were brought by the mothers of 24 infants with intussusception and of 15 controls. The teats were tested by placing them on an inverted burette and timing the flow of $10 \mathrm{ml}$. of tap-water. Two convenient marks were made on the burette so that the pressure was standardized : the heights of the marks from the lower end of the inverted burette were in fact 37 and $47 \mathrm{~cm}$., giving a mean pressure of $42 \mathrm{~cm}$. at the end of the burette, or 43 to $45 \mathrm{~cm}$. at the tip of 
the teat, depending on the type. The mean of five readings was calculated for each teat, the teat being detached and reattached after each reading.

These values are given in Table IV, and when more than one teat was supplied the result for the fastest is presented. We have also indicated in the same table the children receiving added cereal in their bottle-feeds.

TABLE IV.-Flow-times of Teats Expressed as Seconds per $10 \mathrm{ml}$. Water at $44 \mathrm{~cm}$. Mean Pressure

\begin{tabular}{|c|c|c|c|c|}
\hline & \multicolumn{2}{|c|}{ Cases of Intussusception } & \multicolumn{2}{|c|}{ Controls } \\
\hline & $\begin{array}{l}\text { Flow- } \\
\text { time }\end{array}$ & $\begin{array}{l}\text { Whether } \\
\text { Thickened }\end{array}$ & $\begin{array}{l}\text { Flow- } \\
\text { time }\end{array}$ & $\begin{array}{l}\text { Whether } \\
\text { Thickened }\end{array}$ \\
\hline & $\begin{array}{c}0.5 \\
1.2 \\
1.8 \\
1.9 \\
2.2 \\
2.4 \\
4.43 \\
5.0 \\
7.2 \\
8.2 \\
12.6 \\
13.3 \\
14.6 \\
14.8 \\
15.4 \\
16.3 \\
18.4 \\
19.6 \\
25.7 \\
26.4 \\
29.4 \\
29.6 \\
48.0 \\
51.5\end{array}$ & $\begin{array}{l} \pm \\
\pm \\
\pm \\
\pm \\
\pm \\
\pm \\
\pm \\
\pm \\
\pm \\
\pm \\
\pm \\
\pm \\
\pm \\
\pm\end{array}$ & $\begin{array}{r}2.7 \\
4.3 \\
5.0 \\
5.1 \\
7.1 \\
17.9 \\
18.3 \\
25.4 \\
25.9 \\
26.6 \\
29.7 \\
30.4 \\
31.6 \\
47.5 \\
80.5\end{array}$ & $\begin{array}{l}+ \\
\pm \\
\pm \\
\pm \\
\pm \\
= \\
= \\
\pm \\
\pm \\
+\end{array}$ \\
\hline \multirow[t]{2}{*}{$\begin{array}{c}\text { Mean } \\
\text { time }\end{array}$} & 15.43 & & 23.87 & \\
\hline & & $18 \cdot 67$ & & \\
\hline
\end{tabular}

The mean flow-time for the teats used by the children with intusssusception was less than that for teats used by controls, although the difference was not quite significant at the $5 \%$ level. However, the apparent interaction between thickening of feeds and the occurrence of the disease could be relevant here, since the rate of flow in these circumstances will differ considerably from the tap-water measurements. Reviewing only those readings where cereals were not added, we have 12 out of 19 teats of intussusception cases giving readings of 17 . seconds or less, but only 1 of the 9 controls. At this particular although arbitrary level of 17 seconds the difference is statistically significant at the $5 \%$ level. Expressed as proportions of all infants in the groups and not just those who were bottle-fed, the difference in the proportions with both fast teats and unthickened feeds is even more striking, although the failure of some mothers to supply the teats renders exact comparison impossible. In all 12 cases of intussusception with fast teats the onset was between 5 a.m. and 3 p.m.

It was clear from the appearance of the teats that many mothers had found the rates of flow unacceptable when the teats were new. In 10 cases and 3 controls the holes had been enlarged with either knife or scissors through snipping the end of the teat, or cutting it off, or connecting separate holes. This difference is also statistically significant. Other teats had added perforations or more conservative enlargements.

There is a strong suggestion from these various items of information that infants with intussusception are presented with their fluids more precipitately than are unaffected infants.

To pursue this further a number of new teats were bought and tested under conditions similar to those above and the results are given in Table V. No attempt was made to estimate the variability of individual makes, but there were very wide variations, and comparison with the teats used in both groups shows how unacceptable these rates prove to most mothers. There seems to be a real need for some manufacturers to make holes

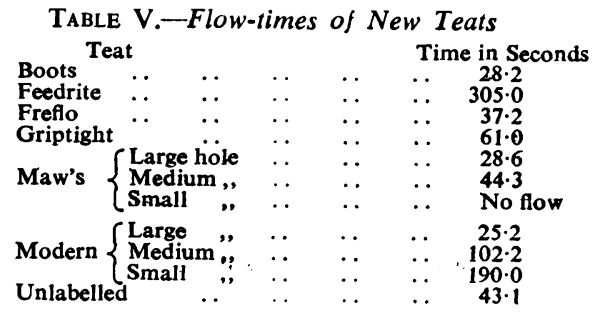

of more realistic sizes and for all of them to label their teats in a standard and meaningful way so that mothers may know what they are buying and doctors and nurses can advise them on what to get. An initial flow rate of 20 to 25 seconds under the above conditions should be safe and at the same time prove acceptable to most mothers of children in this age-groutp.

\section{General Dietary Features}

Mothers were questioned about other features of the diet, particularly the types of food, the ages at starting and the recent quantities of bread and cereals, fruit and vegetables, protein foods, beverages, confectionery, and vitamin supplements. The picture showed wide variation, but no differences were noted between the two groups in any of these respects.

Mothers were also asked whether their children had any unusual tastes; some of the " unusual " foods were ice-cream, sardines, gherkins, pickles, cucumber, crab, tomatoes, cheese, celery, tea, and olive oil. None was especially related to the intussusception group.

\section{Feeds Before the Onset}

Special attention was paid to the three feeds immediately preceding the onset of the disease. At the last feed, 10 of the 35 infants with intussusception were said to have taken less than the usual amount, three were said to have demanded an extra feed that they did not usually get, and the other feeds were not thought to be unusual. The only lumpy foods recorded were celery, boiled potato, apple, and fried potato chips. The latter three were all in older children and seemed reasonable items of diet, but the celery was eaten by a 5-monthsold child. Because foreign bodies in the bowel can cause intussusception it seemed possible that the celery, and a lump of coal swallowed by another child, could be related to the disease.

Nothing striking was seen in the two feeds preceding the last one. Attempts at controlling observations on recent feeds did not prove practicable.

\section{Drugs}

A possible analogy with pink disease (which until recently also had a high incidence in the North-east of England) led us to inquire into the ingestion of "teething powders" and other drugs before the onset of symptoms. For obvious reasons the most important of these inquiries concerned purgatives.

Fourteen children in each group had had "teething powders" at some time. The most frequently given of these was Steedman's soothing powders, the main 
active principle of which is phenolphthalein, about $50 \mathrm{mg}$. per powder. Less frequently given were Ashton and Parsons' infants' powders, a simple carminative, and Fennings's children's cooling powders, containing bromvaletone, phenacetin, glycyrrhiza, and magnesium oxide.

"Magnesia " was given to 29 of the 35 with intussusception and 24 of the 32 controls, the combined frequency corresponding exactly with the $79 \%$ measured by Creery (1955) in Belfast. This was usually given either as Phillips' milk of magnesia or as Dinneford's pure fluid magnesia, or sometimes as both simultaneously and for different reasons. The former contains magnesium oxide $8.45 \%$, and the latter magnesium bicarbonate $2.5 \%$. Expressed as weight/ volume of magnesium the former is therefore about seven times as concentrated as the latter.

Other purgatives given included syrup of figs (mainly senna) in one case and grey tablets (33\% mercury) in another.

When the time and doses of purgatives were considered in detail there was evidence of a difference between the groups. If one teaspoonful of Phillips' milk of magnesia or of syrup of figs, one Steedman's powder, and one grey tablet are each regarded as one unit of purgation, and the other preparations are discounted, the frequency distribution of units administered in the four days before onset can be expressed as in Table VI. The difference between the two distributions can be considered significant.

\begin{tabular}{|c|c|c|c|c|c|c|c|}
\hline \multirow{2}{*}{ Group } & \multicolumn{6}{|c|}{ Units } & \multirow{2}{*}{ Total } \\
\hline & $<1$ & -2 & -4 & -6 & -8 & -10 & \\
\hline $\begin{array}{l}\text { Intussusception } \\
\text { Control }\end{array}$ & $\begin{array}{l}24 \\
26\end{array}$ & $\begin{array}{l}1 \\
3\end{array}$ & $\begin{array}{l}5 \\
3\end{array}$ & $\begin{array}{l}2 \\
0\end{array}$ & $\begin{array}{l}1 \\
0\end{array}$ & $\begin{array}{l}2 \\
0\end{array}$ & $\begin{array}{l}35 \\
32\end{array}$ \\
\hline
\end{tabular}

High doses usually resulted from administration of different preparations simultaneously and for different reasons, their true pharmacological actions being often unknown to the mother and not always stated on the labels.

\section{Evidence Relating to Possible Infection}

Symptoms in the two weeks preceding the onset of intussusception or the interview were asked for in both groups: 19 patients and 19 controls complained of such symptoms ; 12 patients and 16 controls complained of respiratory symptoms, mainly running noses ; 5 patients and 2 controls complained of diarrhoea, vomiting, constipation, or abdominal pain; 2 patients and 1 control had had unlocalized illnesses with anorexia and fever. Earlier illnesses were also recorded, but no differences between the groups were detected.

Inquiry was made of illnesses within the family in the previous month. Twenty families complained of such illness-12 with intussusception and 8 controls-all of which were respiratory conditions except a family attack of dysentery one week before the onset of an intussusception.

There is nothing in these contact histories or in the accounts of earlier illnesses and symptoms which lends clear support to the accumulating evidence that viruses play an important part in the causation of intussusception.

\section{Parents' Opinion}

The mothers of 35 intussusception patients were asked if they had any idea of the cause of the illness. Many had none at all or blamed some of the dietary features already mentioned, others gave entirely unconvincing explanations. But there was one interesting group of replies. Nine mothers thought it was due to some form of violence-" a rough game," "turning somersaults," " being lifted excessively by an older child," " jumping," " father clipped her," "fell and twisted herself," " rough treatment by father," " joggling in a van."

\section{Discussion}

Many of the results from these inquiries are negative, and where different results impinge upon the same aspect of the disease they sometimes invite contradictory conclusions. However, some steps towards a synthesis can be taken.

Evidence for dietary factors comes from two main sources. The first is the traditional clinical impression that affected babies are unusually heavy, and we found support for this; it seemed to apply particularly to infants under 5 months of age, and as their birth weights were normal this represents an increased rate of growth.

The second source is the difference we observed between the flow rates of the teats used by infants with intussusception and by the controls. The evidence does not allow us to imply a direct cause-and-effect relationship between increased flow rates and intussusception. Although it is possible that the rate of build-up of the fluid load (or the concurrent intake of swallowed air or both) is directly causal, we are not able, from our data, to differentiate this from some indirect association.

However, the larger holes in the teats, the less frequently thickened feeds, and a preponderance of bottle-feeding together suggest a real difference, in a general if not in a specific sense, between the feeding of infants with intussusception and that of controls.

The interpretation of the diurnal variation in the times of onset is difficult. In view of the evidence for anomalies of feeding technique it is tempting to attribute this variation to a direct effect of individual feeds. However, the detailed study of the time relationships between onset and previous feed failed to confirm a direct or at least an immediate effect. The three main possibilities are these: that the diurnal variation is related to the general level of natural peristaltic activity at different periods of the day and not to individual feeds, that rapid fluid-loading has a delayed rather than an immediate effect, or that there is a latent interval of some hours between the true onset of invagination and the first symptom.

An observation of possible importance in relation to feeding was published by Mooro (1924) from Cairo. He reported two cases of intussusception in male adult Moslems who during the fast of Ramadan denied themselves all fluids from sunrise to sunset : one was affected immediately after drinking and the other as he was about to do so. Here is the same contradiction: association with heavy intermittent fluid-loading, yet in one case a long period since the last intake.

The question of foreign bodies and of lumpy foods has been raised repeatedly in the past, and the former has often been proved in individual cases, particularly 
adults. In the series of 35 cases there was only one child who swallowed a foreign body, one who ate at the last feed what might be regarded as an unsuitable food (celery at 5 months), and three others where the food might possibly have been related. These observations could not be controlled, but they remind us that a small proportion of intussusceptions are probably so caused.

Purgatives also come under proper suspicion, and the present evidence indicates that they may be an important factor in some children. Purgatives may well merit further inquiry, particularly if a more objective and quantitative method than the mothers' accounts can be devised.

Clinical evidence of infection and evidence of contact were remarkable for their absence. This is in keeping with the absence of a seasonal distribution in our own material and in other recent studies, and the absence of birth-rank differentials in incidence (MacMahon, 1955). These facts together seem at first sight to contradict the convincing laboratory evidence regarding infection. Gardner (1961), in Newcastle, examined the stools of 10 children with intussusception and found adenovirus in six and herpes simplex virus in one. Ross and Potter (1961), in Sheffield, made similar observations. Zachary and Potter (1961) further demonstrated differing virus recovery rates in children with intussusception and in some unaffected children, and high or rising titres of antibodies in the sera of those affected. Our more recent work in Newcastle confirms this : 28 more cases of intussusception have been examined and adenovirus recovered from 15 , and evidence of herpes simplex was found in four. In four of these cases identical adenovirus was recovered from mesenteric lymph nodes.

Serological evidence of recent virus infection with herpes simplex or adenovirus has been demonstrated in nine affected children; a very much lower rate of recovery of adenovirus has been obtained in several sets of controls. The selection of controls presented a difficulty, as normal children in closed communities may excrete non-epidemic types of adenovirus for long periods (Gardner, Wright, and Hale, 1961). It has been shown occasionally that adenovirus may cause diarrhoea (Gardner, McGregor, and Dick, 1960), and in the study referred to it was due to the epidemic type 7 . It is for these reasons that we selected our controls in a number of different ways. Full details will be published in due course.

A possible explanation of the apparent contradiction between the clinical and epidemiological data and the laboratory evidence may be found in the types of virus isolated. All but two of the adenoviruses so far isolated in Newcastle have been of the non-epidemic types 1,2 , 5 , and 6 ; the two exceptions belonged to types 4 and 7 . Our clinical evidence suggests that the adenoviruses commonly isolated in this disease do not seem to be agents which consistently give rise to other recognized symptoms. However, in studies rvhere seasonal distributions have been found (Fitzwilliams, 1908 ; Sheh, $\mathrm{Ma}$, Yang, and Sun, 1957) it is possible that the proportionate frequencies of the various virus types involved may have differed from our own material.

A further point of interest with respect to the type of virus isolated is that two of the cases from which herpes virus was isolated have since recurred, but none of those with adenovirus.
There appears to be a widespread and growing assumption that the aetiology of intussusception in children is a simple matter of a virus infection. We feel that this is an over-simplification and that the right question to ask is, "How important is adenovirus or herpes simplex virus infection of the bowel and what is its relationship to the other factors?" We know that adenoviruses may be excreted for long periods in closed communities, and in one such infected group of children in a residential nursery observed over a considerable period not a single ca:se of intussusception occurred (Gardner et al., 1961). Perhaps this was due in part to a well-trained staff and proper techniques of feeding. It seems most probable that in many cases of intussusception both the virus infection of the bowel and one of the other precipitating factors are necessary and one alone will not commonly give rise to the disease.

The conviction of a number of parents that trauma had played some part was interesting, and this probability has been raised before. Eliot and Corscaden (1911) reviewed 300 cases of intussusception in adults, and concluded that there was an adequate explanation in terms of injury for 23 of them. Some were a little far-fetched; but 17 followed immediately upon a violent strain, wrench, or jolt such as lifting heavy weights or other exertion, and one case occurred in a vaudeville performer who supported the weights of several members of his audience standing on his abdomen. All we can say is that the possible association with trauma is suggestive.

If intussusception has the complex aetiology that we suspect, it would hardly be surprising if the different determining factors did not vary in emphasis from time to time.

\section{Summary}

An attempt has been made to re-examine the dietary and infective theories of the origin of intussusception. The findings show: (1) That affected infants under 5 months of age were above average weight for age, and with normal birth weights they must have grown more rapidly than average children. (2) That affected children were bottle-fed more often and had their feeds thickened less frequently than controls. They had larger holes in the teats of their bottles and were probably given their fluids more rapidly. (3) That there is a diurnal variation in the time of onset, with the greatest frequency during the day. (4) That miscellaneous factors, especially lumpy foods, purgation, foreign bodies, and trauma, may occasionally play some part. The widespread use of recognized and unrecognized purgatives in infants should be noted.

Controlled clinical 'observation supporting the infective basis of intussusception was not obtained, but the viruses recovered from the cases were of nonepidemic types, and are either asymptomatic, apart from intussusception, or produce symptoms with insufficient regularity to be detected in this way.

We suspect that intussusception has a complex aetiology; that in many cases more than one factor is involved and that some of these will vary in emphasis in different communities at different times.

We are indebted to Dr. R. C. M. Pearson, Medical Officer of Health for Newcastle upon Tyne, for his assistance in obtaining control material, and to the Eugenics Society for financial support for a research programme of which this study is part. 
REFERENCES

Court, S. D. M., and Knox, E. G. (1959). Brit. med. J., 2, 408. Creery, R. D. G. (1955). Ibid., 2, 178

Eliot, E., and Corscaden, J. A. (1911). Ann. Surg., 53, 169

Fitzwilliams, D. C. L. (1908). Lancet, 1, 628, 709.

Gardner, P. S. (1961). Brit. med. J., 2, 495.

- McGregor, C. B., and Dick, K. (1960), Ibid, 1, 91.

Wright, A. E., and Hale, J. H. (1961). Ibid., 2, 424.

MacMahon, B. (1955). Amer. J. hum. Genet., 7, 430.

Ministry of Health (1959). Public Health and Medical Subjects Report No. 99. H.M.S.O., London

Mooro, A. W. (1924). Brit. med. J., 1, 319.

Ross, J. G., and Potter, C. W. (1961). Lancet, 1, 81.

Sheh Ya Hsiung, Ma An Ch'uan, Yang Yung-K'ang, and Sun Chien-Min (1957). Chin. med. J., 75, 409.

Smith, I. McD. (1960). Brit. med. J., 1, 551.

Steyn, J., and Kyle, J. (1961). Ibid., 1, 1730.

Zachary, R. B., and Potter, C. W. (1961). Proc. roy. Soc. Med., 54, 1018 .

\section{VIRUS INFECTION AND INTUSSUSCEPTION IN CHILDHOOD}

BY

\section{P. S. GARDNER, M.D., Dip.Bact.}

E. G. KNOX, M.D., M.R.C.P.

S. D. M. COURT, M.D., F.R.C.P.

AND

C. A. GREEN, M.D., Ph.D., D.P.H.

From the Departments of Bacteriology and Child Health, United Hospitals and King's College, Newcastle upon Tyne

The association of adenovirus infection and intussusception has been suspected since the work of Gardner (1961) and Ross and Potter (1961), but satisfactory proof of a causal role has proved difficult. Knox et al. (1962) discussed the interrelations of various factors, including infection, in the aetiology of intussusception and showed that a number of determinants exist, but contended that no single cause was always followed by the disease or was always present before the disease. In addition to the existence of several causal factors which could vary in importance in different communities, they pointed out the difficulties of ascertaining the prevalence of adenovirus in a general population of the same age, especially the selection of a control group of normal children. Children admitted to hospital for purposes other than the treatment of intussusception can scarcely be regarded as normal, since adenoviruses are known to play a part in a variety of diseases of the respiratory and alimentary tracts.

In these conditions it has been shown that adenovirus may be excreted in large quantity in the stool (Kjellen et al., 1957a, 1957b ; Gardner et al., 1960 ; Duncan and Hutchinson, 1961), but there is conflicting evidence as to their role in diarrhoea. Ramos-Alvarez and Sabin (1958) and Sommerville (1958), in two surveys of diarrhoea, found no increase in the incidence of adenovirus, but this is in contrast to other workers (Gardner et al., 1960 ; Kjellén et al., 1957a, 1957b ; Kendall et al., 1957 ; Duncan and Hutchinson, 1961), who have found the epidemic types of adenovirus associated with diarrhoea, often, but by no means invariably, in conjunction with respiratory illness. All workers agree that when an adenovirus causes respiratory illness it may be excreted in the stool. Residential nurseries where infants and pre-school children can readily be studied are unsuitable, for if an adenovirus infection is present in such a closed community all will be infected and many will excrete adenovirus for many months (Gardner et al., 1961). Child welfare centres are probably capable of supplying the best source of material for comparison but have the disadvantage that it is unjustified to obtain repeated samples of venous blood from normal children.

For these reasons, and because it is difficult to rely upon any single source of material as an indication of population prevalence, we felt it essential for a conclusive demonstration of the role of adenovirus the aetiology of intussusception that a variety of controls should be used.

To substantiate the view that intussusception was a systemic infection it is necessary to show evidence of a generalized infection besides the faecal excretion, and so, whenever possible, both paired sera and mesenteric lymph nodes removed at operation were studied for evidence of virus infection.

If adenoviruses are causally associated with intussusception other viruses multiplying in the alimentary tract might be associated with intussusception too. We hope to show that this is true.

The main objective of this study was to measure the incidence of virus infections in children with intussusception and their timing in relation to the onset, and to compare the results with those obtained from a variety of control groups described below.

\section{Materials and Methods}

Selection of Cases of Intussusception.-All affected children admitted to the wards of the Royal Victoria Infirmary from June, 1961, to June, 1962, were accepted for the investigation. In all, 38 cases were obtained.

Selection of Control Cases.-These were divided into three groups. (1) Diarrhoeal group: All children in the age-group of 3 to 12 months with diarrhoea admitted to Walkergate Hospital over the same period of time were used. This provided a total of 62 cases. (2) Bronchiolitis and pneumonia group: During the period of study an investigation into the role of viruses in acute bronchiolitis and in pneumonia was running concurrently and it was decided to use cases of an appropriate age for an additional control. (3) Normal children : Eight children were selected from the teaching hospital child welfare centre and samples of faeces collected for investigation at regular intervals during their first year of life. Two members of the staff whose wives had babies during the period of study allowed us to use their infants as additional controls.

Techniques for Virus Isolation.-Faeces from all cases of intussusception and the three sets of controls were examined on HeLa cells and monkey-kidney-tissue cultures. The majority of these specimens were examined on Hep 2 cells. Throat swabs were examined in an identical manner. The methods of isolation and identification of herpes simplex virus and adenovirus have been adequately described in previous publications (Munro-Ashman et al., 1958 ; Gardner, 1961), and the methods in this study were similar to these. If an enterovirus was suspected the appropriate antisera were used in a neutralization test. In 21 of the 38 children with intussusception a surgeon removed a mesenteric lymph node at operation for attempted virus isolation. 